\title{
Risk factors associated with postoperative pain after ophthalmic surgery: a prospective study
}

This article was published in the following Dove Press journal:

Therapeutics and Clinical Risk Management

22 January 2016

Number of times this article has been viewed

\author{
Mladen Lesin ${ }^{1, *}$ \\ Mirna Dzaja Lozol,* \\ Zeljka Duplancic-Sundov' \\ Ivana Dzaja' \\ Nikolina Davidovic ${ }^{2}$ \\ Adriana Banozic ${ }^{3}$ \\ Livia Puljak ${ }^{3}$ \\ 'Department of Ophthalmology, \\ ${ }^{2}$ Department of Psychiatry, University \\ Hospital Split, ${ }^{3}$ Laboratory for Pain \\ Research, University of Split School \\ of Medicine, Split, Croatia \\ *These authors contributed equally \\ to this work
}

Background: Risk factors associated with postoperative pain intensity and duration, as well as consumption of analgesics after ophthalmic surgery are poorly understood.

Methods: A prospective study was conducted among adults $(\mathrm{N}=226)$ who underwent eye surgery at the University Hospital Split, Croatia. A day before the surgery, the patients filled out questionnaires assessing personality, anxiety, pain catastrophizing, sociodemographics and were given details about the procedure, anesthesia, and analgesia for each postoperative day. All scales were previously used for the Croatian population. The intensity of pain was measured using a numerical rating scale from 0 to 10 , where 0 was no pain and 10 was the worst imaginable pain. The intensity of pain was measured before the surgery and then 1 hour, 3 hours, 6 hours, and 24 hours after surgery, and then once a day until discharge from the hospital. Univariate and multivariate analyses were performed.

Results: A multivariate analysis indicated that independent predictors of average pain intensity after the surgery were: absence of premedication before surgery, surgery in general anesthesia, higher pain intensity before surgery and pain catastrophizing level. Independent predictors of postoperative pain duration were intensity of pain before surgery, type of anesthesia, and selfassessment of health. Independent predictors of pain intensity $\geq 5$ during the first 6 hours after the procedure were the type of procedure, self-assessment of health, premedication, and the level of pain catastrophizing.

Conclusion: Awareness about independent predictors associated with average postoperative pain intensity, postoperative pain duration, and occurrence of intensive pain after surgery may help health workers to improve postoperative pain management in ophthalmic surgery.

Keywords: postoperative pain, factors, personality, psychology, affect, pain catastrophizing, sociodemographics

\section{Introduction}

Studies conducted in hospitals indicate that up to $75 \%$ of patients suffer from pain after surgical procedures, with up to $30 \%$ patients suffering from moderate or intense postoperative pain. ${ }^{1-3}$ Preventive and effective management of pain may improve clinical outcomes, prevent the development of complications, reduce health care costs, and improve patients' quality of life. ${ }^{4}$ Furthermore, International Association for the Study of Pain (IASP) has proclaimed that pain management is a fundamental human right. ${ }^{5}$

Postoperative pain in ophthalmic surgery has been continuously neglected and underestimated. ${ }^{6}$ An article published in a nursing journal in the year 2006 questioned whether the pain needed to be measured at all in patients with cataract surgery, ${ }^{7}$ although it was well documented that ophthalmic surgical procedures can inflict very intense postoperative pain. ${ }^{8}$ There are assumptions that ophthalmic surgery causes little if any postoperative pain, due to the limited surgical trauma compared to other surgical
Correspondence: Livia Puljak

Laboratory for Pain Research, University of Split School of Medicine, Soltanska 2, 21000 Split, Croatia

Tel +38521557807

Fax +385215578 II

Email livia@mefst.hr submit your manuscript | www.dovepress.com

Dovepress

http://dx.doi.org/10.2147/TCRM.S97024
Therapeutics and Clinical Risk Management 2016:12 93-102

(c) (i) () 2016 Lesin et al. This work is published and licensed by Dove Medical Press Limited. The full terms of this license are available at https://www.dovepress.com/terms.php BV and incorporate the Creative Commons Attribution - Non Commercial (unported, v3.0) License (http:///creativecommons.org/licenses/by-n/3.0/). By accessing the work you for commercial use of this work, please see paragraphs 4.2 and 5 of our Terms (https://www.dovepress.com/terms.php). 
disciplines. However, in ophthalmic surgery, short-acting anesthetic agents are preferred to enable rapid recovery from anesthesia, which contributes to the development of early postoperative pain. ${ }^{8}$ A study about pain intensity in elective ophthalmic surgery indicated that, depending on the type of surgery, the prevalence of severe pain intensity ranges from $13.8 \%$ after procedures such as cataract, iridectomy, and anterior chamber revision, to $53.8 \%$ after procedures such as encircling band, strabismus surgery. ${ }^{8}$

Underestimating postoperative pain in analgesia leads to insufficient pain management. It has been shown that less than half of patients undergoing major ophthalmic surgery receive postoperative analgesia and a majority of them receive it only once. ${ }^{9}$

Since postoperative pain is one of the most commonly reported postoperative symptoms, knowing predictive factors for postoperative pain may facilitate early intervention and better pain management. ${ }^{10}$ Factors associated with postoperative pain can be summarized into four categories, including demographic and psychological factors, preoperative pain, and surgical factors. ${ }^{11}$ Many of these factors can be analyzed only as a self-report, just like the pain itself. There are no objective measures of pain intensity, and pain has been defined as being "whatever the patient says it is."

However, little is known about independent factors associated with postoperative pain in ophthalmic surgery. Our recent systematic review about factors associated with postoperative pain and analgesic consumption in ophthalmic surgery found a limited number of very heterogeneous studies on factors associated with postoperative pain, with a number of limitations and inadequate statistics for determining independent factors. ${ }^{12}$ Therefore, we conducted a prospective study on factors associated with postoperative pain intensity and duration including demographic, psychological, preoperative pain and surgery-related factors as predictors, as well as on consumption of analgesics after ophthalmic surgery.

\section{Methods}

\section{Ethics}

The study was approved by the Ethics Committee of the University Hospital Split (approval registration number: Class: 530-02/13-01/46, Ur.br.: 2181-147-06/J.B.-13-2). All patients signed a written consent form for participation in the study.

\section{Setting}

This prospective study without a control group was conducted at the Department of Ophthalmology, University Hospital
Split, Croatia from October 2013 to April 2015. Patients were enrolled into the study consecutively until the pre-specified target numbers of participants were reached.

\section{Participants}

Adult patients (age $\geq 18$ years) who underwent eye surgery were included in the prospective observational study $(\mathrm{N}=226)$.

The surgical procedures that qualified for inclusion criteria were pars plana vitrectomy, scleral buckling procedures, deep sclerectomy for glaucoma, evisceration, enucleation, and external dacryocystorhinostomy, extensive reconstructions (due to tumors etc), cataract surgery, glaucoma surgery, and plastic ophthalmic surgeries. For the purpose of comparison, surgical procedures were classified into those that are simple and complex, whereas complex procedures were defined as those that were not performed in local/regional anesthesia and that require extensive tissue damage, as published previously. ${ }^{9}$

The exclusion criteria were inability to communicate (including impairment of sensorium), inability to give informed consent, and mental illness.

\section{Study protocol}

Shortly after hospitalization, patients received written information about the study and signed informed consent. A day before surgery, patients filled out the following questionnaires: International Personality Item Pool (IPIP)-50 scale, anxiety questionnaire (STAI-6) Pain Catastrophizing Scale (PCS), Positive and Negative Affect Schedule (PANAS), and sociodemographic questionnaire. All these questionnaires have been used previously in Croatian language and validated.

The following sociodemographic data were collected: age, sex, height, weight, education level, monthly income, marital status, employment status, and subjective assessment of personal health.

The other collected data included: type and dose of premedication, preoperative patient's physical status according to the American Society of Anesthesiologists (ASA) Physical Status classification, type of procedure, duration of procedure, the type and dose of anesthesia, and the type and dose of analgesia for each postoperative day spent in hospital. Pain intensity was measured with Numerical Rating Scale (NRS) ranging from 0 to 10 , where 0 is no pain, and 10 is the worst imaginable pain. The NRS was used because patients may suffer significant visual impairment for a short time after ophthalmic surgery. 
Pain intensity was first measured a day before surgery at the same time when questionnaires were administered. Postoperative pain intensity was measured 1 hour, 3 hours, 6 hours, and 24 hours after surgery, continuing with pain assessment once daily until discharge from the hospital. According to the protocol, patients with pain intensity $\geq 4$ out of ten on the day of discharge were supposed to be telephoned again 1 week after the discharge for assessment of pain intensity. If pain did not subside, pain intensity was supposed to be assessed again once weekly until 1 month after discharge.

\section{Statistics}

Based on the study of Henzler et al, intensive pain (defined as value $\geq 5$ out of 10 on visual analog scale [VAS]) was found in $51.5 \%$ of patients operated under major ophthalmic procedures and in $19 \%$ operated in minor ophthalmic procedures. ${ }^{8}$ With statistical power analysis, we calculated that with alpha $=0.05$ and statistical power of $90 \%$, we need at least 35 participants in the group with intensive pain ( $\geq 5$ on VAS) 1 hour after surgery and 35 in the group with $<5$ on VAS 1 hour after surgery. In order to make sure that there will be a sufficient number of patients with intense pain, patients were included consecutively in the study until there were at least 35 patients with intense pain.

For analyses, patients were sorted into groups based on studied variables. Descriptive data were shown as mean and standard deviation, or median and range, depending on the normality of distribution. Risk ratios and $95 \%$ confidence intervals (CI) were calculated for the study variables for the risk of having pain intensity of NRS $\geq 5$. Mann-Whitney and Kruskal-Wallis tests were used for data with distribution asymmetry and independent $t$-test for data with normal distribution. To examine the correlation between pain intensity and pain duration with other continuous variables, we calculated Pearson's $r$ coefficient. Significant predictors of pain intensity and pain duration were analyzed using linear regression while predictors of pain intensity $\geq 5$ were analyzed using logistic regression. Postoperative pain intensity in different time points was analyzed using nonparametric test for repeated measurements (Friedman test) because of distribution asymmetry. Pain intensity data were normalized using a logarithmic transformation to obtain the normal distribution of residuals for regression analysis. Statistical significance was set at $P<0.05$.

\section{Results}

Among 226 patients, there were 93 (41\%) men and 133 $(59 \%)$ women. Their average age was $67 \pm 13$ years, and the average body mass index was $26.7 \pm 3.9$. When asked to make a subjective assessment of their health, the majority indicated their health as "good" $(\mathrm{N}=95,42 \%)$ or average $(\mathrm{N}=94,41 \%)$, while the remaining patients indicated their health was "very good" $(\mathrm{N}=22,9.7 \%)$, "bad" $(\mathrm{N}=10,4.4 \%)$ or "very bad" $(\mathrm{N}=1 ; 1.8 \%)$.

Majority of patients were operated in general anesthesia $(\mathrm{N}=126,55.8 \%)$ or local anesthesia with lidocaine $(\mathrm{N}=99$, $43.9 \%)$ or tetracaine $(\mathrm{N}=1)$. The most common procedure was cataract under local anesthesia and pars plana vitrectomy. Most of the patients operated under general anesthesia had an ASA status of 2 or 3 , indicating patients with mild or serious systemic diseases (Table 1).

Most of the patients had a high school education and family monthly net income under 750 USD. Low family income may be explained by the fact that the majority of the patients were retired. Most of the patients were married or had a domestic partner (Table 2).

Average pain intensity was the highest 1 hour after the surgery (Figure 1). Among patients operated under general anesthesia, there were $41(34 \%)$ of patients with pain intensity $\geq 5$ in the first 6 hours. In the whole sample, there were 45 (20\%) of patients with pain intensity $\geq 5$ in the first 6 hours. After 7 days, postoperatively, none of the patients had pain intensity $\geq 5$.

Premedication before the surgery was given to 151 (67\%) patients; all of them received benzodiazepines, including 145 patients who got diazepam and six patients who got midazolam.

Table I Surgical procedures and ASA status of patients

\begin{tabular}{ll}
\hline Variable & $\mathbf{N}(\%)$ \\
\hline Type of the procedure & \\
Cataract surgery under local anesthesia & $92(40.7)$ \\
Pars plana vitrectomy & $77(34)$ \\
Scleral buckling procedures & $12(5.3)$ \\
External dacryocystorhinostomy & $11(4.9)$ \\
Glaucoma surgery & $8(3.5)$ \\
Extensive reconstructions (tumors) & $7(3)$ \\
Enucleation & $6(2.7)$ \\
Cataract surgery under general anesthesia & $5(2.2)$ \\
Plastic surgery in local anesthesia & $4(1.8)$ \\
Evisceration & $3(1.3)$ \\
Glaucoma and cataract surgery in local anesthesia & $1(0.4)$ \\
ASA status, N (\%) & \\
I. Normal healthy patient & $20(16)$ \\
2. A patient with mild systemic disease & $78(62)$ \\
3. A patient with severe systemic disease & $26(2 \mathrm{I})$ \\
4. A patient with severe systemic disease that is a & $0(0)$ \\
constant threat to life & \\
No information & $2(1)$ \\
\hline Note: ASA status is the patient health status according to the American Society of \\
Anesthesiologists (ASA).
\end{tabular}


Table 2 Economic status of the patients

\begin{tabular}{ll}
\hline Variable & N (\%) \\
\hline Education & \\
No primary school & $19(8.4)$ \\
Primary school & $50(22.1)$ \\
High school & $115(50.9)$ \\
Two-year university education & $20(8.8)$ \\
Four-to-six year university education & $18(8)$ \\
Masters' or doctoral degree & $1(0.4)$ \\
No response & $3(1.3)$ \\
Monthly family net income & \\
Under 750 USD & $133(58.9)$ \\
75 I-I,499 USD & $82(36.3)$ \\
Above I,500 USD & $5(2.2)$ \\
No response & $6(2.7)$ \\
Employment & \\
Employed & $20(8.8)$ \\
Unemployed & $6(2.7)$ \\
Retired & $157(69.5)$ \\
No response & $43(19)$ \\
Marital status & \\
Married or with a domestic partner & $73(32.3)$ \\
In a relationship & $\mathrm{I}(0.4)$ \\
Single & $\mathrm{I}(0.4)$ \\
Divorced & $5(2.2)$ \\
Widowed & $10(4.4)$ \\
No response & $135(59.7)$ \\
\hline Abbreviani USD, US &
\end{tabular}

Abbreviation: USD, US dollar.

After the surgery, patients operated under general anesthesia received different drugs in the operating room. Few patients received only one drug, including metoclopramide $(\mathrm{N}=1)$, atropine $(\mathrm{N}=4)$ and neostigmine bromide $(\mathrm{N}=3)$. Most of the patients received a combination of two drugs, including atropine and metoclopramide $(\mathrm{N}=1)$, atropine and ranitidine hydrochloride $(\mathrm{N}=46)$, neostigmine bromide and

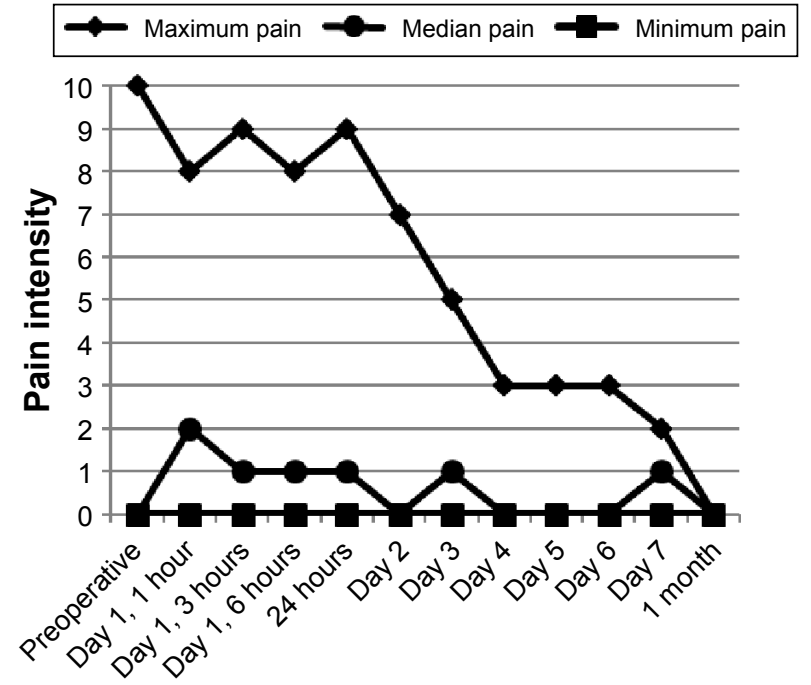

Figure I Maximum, median, and minimum pain intensity measured preoperatively and multiple times after the surgery.

Note: Pain intensity: $0=$ no pain and $10=$ worst possible pain. metoclopramide $(\mathrm{N}=51)$, neostigmine bromide and ranitidine hydrochloride ( $\mathrm{N}=4)$, neostigmine bromide and diclofenac $(\mathrm{N}=1)$, as well as diclofenac and ranitidine hydrochloride $(\mathrm{N}=1)$. Four patients received a combination of three drugs in the operating room after the procedure: neostigmine bromide, diclofenac, and metoclopramide. Some patients did not receive any medications in the operating room after the surgery $(\mathrm{N}=10)$.

Postoperative analgesia was administered to $52(23 \%)$ of patients and for most of them only on the first postoperative day. The most commonly administered analgesics were diclofenac and metamizole sodium (Table 3). These analgesics were administered only to patients operated under general anesthesia. Patients operated under local anesthesia did not receive a single analgesic. These patients received a local injection with a combination of corticosteroids and anesthetics.

\section{Factors associated with postoperative pain intensity}

On the univariate level, a number of factors were associated with average pain intensity of all postoperative pain intensity measurements: age, preoperative pain intensity, type of procedure, work status, receiving premedication, type of anesthesia, receiving postoperative analgesia, pain catastrophizing, positive affect, negative affect, anxiety, intellect, and extraversion.

Average postoperative pain intensity reported by patients in all measurements had significant negative correlation with age (Pearson $r=-0.217 ; P<0.001$ ), significant positive correlation with preoperative pain intensity (Pearson $r=0.436$; $P<0.001$ ), significant positive correlation with total Pain Catastrophizing Score (Pearson $r=0.262 ; P<0.001$ ) and all the three PCS subscales including rumination (Pearson $r=0.273 ; P<0.001$ ), magnification (Pearson $r=0.183$; $P<0.006$ ) and helplessness (Pearson $r=0.262 ; P<0.001$ ), significant negative correlation with positive affect on the PANAS scale (Pearson $r=-0.245 ; P<0.001$ ), significant positive correlation with negative affect on the PANAS scale

Table 3 Analgesics administered to patients postoperatively

\begin{tabular}{ll}
\hline Drugs & $\mathbf{N}(\%)$ \\
\hline Diclofenac & $25(\mathrm{II} . \mathrm{I})$ \\
Metamizole sodium & $15(6.6)$ \\
Acetaminophen & $6(2.7)$ \\
Proparacetamol hydrochloride & $3(\mathrm{I} .3)$ \\
Granisetron & $\mathrm{I}(0.4)$ \\
Diclofenac and granisetron & $\mathrm{I}(0.4)$ \\
Proparacetamol hydrochloride & $4(\mathrm{I} .8)$ \\
\hline
\end{tabular}


(Pearson $r=0.191 ; P=0.004$ ), significant negative correlation with intellect as a dimension of personality measured on the IPIP scale (Pearson $r=-0.225 ; P<0.001$ ) and significant negative correlation with extraversion as a dimension of personality measured on the IPIP scale (Pearson $r=-0.225$; $P<0.001)$.

Significantly higher pain intensity in all postoperative measurements was found in patients who underwent more difficult procedures compared to those with simpler procedures (Mann-Whitney $U=161.5 ; P<0.001$ ), patients who were employed compared to those who were unemployed or retired $\left(\chi^{2}=8.643, d f=2, P=0.013\right)$, patients who did not receive any premedication before the surgery compared to those who did (Mann-Whitney $U=2,831 ; P<0.001$ ), patients operated in general anesthesia compared to local anesthesia (Mann-Whitney $U=2,272.5 ; P<0.001$ ) and patients who received analgesics after the surgery compared to those who did not receive analgesics (Mann-Whitney $U=1,432$; $P<0.044)$.

Variables that did not reach statistical significance related to average postoperative pain intensity in all measurements in univariate analyses were sex (Mann-Whitney $U=5,577$; $P=0.365$ ), height (Pearson $r=-0.007, P=0.918$ ), weight (Pearson $r=-0.007, P=0.919)$, ASA status $\left(\chi^{2}=0.748 ; d f=2\right.$, $P=0.688)$, education $\left(\chi^{2}=4.269, d f=2, P=0.118\right)$, family income $\left(\chi^{2}=2.711, d f=2, P=0.258\right)$, subjective assessment of personal health $\left(\chi^{2}=6.400, d f=3, P=0.094\right)$, as well as personality dimensions agreeableness (Pearson $r=-0.026$; $P=0.705$ ), conscientiousness (Pearson $r=0.106 ; P=0.116$ ) and emotional stability (Pearson $r=-0.131 ; P=0.051$ ).
Significant predictors from the univariate analysis were further studied in a multivariate analysis. According to the results of multivariate analysis, independent predictors of higher average postoperative pain intensity in all measurements were: higher preoperative pain intensity, not receiving premedication before the surgery, being operated under general anesthesia and having highest score on a PCS (Table 4).

\section{Factors associated with postoperative pain duration}

On the univariate level, a number of factors were associated with postoperative pain duration (pain duration was calculated as the number of measurements where pain intensity was $\geq 1$ ): age, preoperative pain intensity, type of procedure, subjective patient self-assessment of health, receiving therapy before surgery, type of anesthesia, pain catastrophizing (total and two subscales), positive affect, negative affect, anxiety, intellect/imagination, and extraversion.

Postoperative pain duration had significant negative correlation with age (Pearson $r=-0.152 ; P=0.024$ ), significant positive correlation between pain intensity before surgery (Pearson $r=0.403 ; P<0.001$ ), significant positive correlation with total Pain Catastrophizing Score (Pearson $r=0.204$; $P=0.002$ ) and its two subscales - rumination (Pearson $r=0.204 ; P<0.001$ ) and helplessness (Pearson $r=0.224$; $P<0.001)$, significant negative correlation with positive effect measured with PANAS (Pearson $r=-0.248 ; P<0.001$ ) and significant positive correlation with negative effect measured with PANAS (Pearson $r=0.149 ; P=0.027$ ), significant correlation with total anxiety score (Pearson $r=0.158 ; P=0.018$ ),

Table 4 Results of the multivariate analysis on independent predictors of average postoperative pain intensity on all measurements

\begin{tabular}{|c|c|c|c|c|c|}
\hline \multirow[t]{2}{*}{ Model } & \multicolumn{2}{|c|}{$\begin{array}{l}\text { Nonstandardized } \\
\text { coefficients }\end{array}$} & \multirow{2}{*}{$\begin{array}{l}\text { Standardized } \\
\text { coefficients } \\
\text { Beta }\end{array}$} & \multirow[t]{2}{*}{$t$} & \multirow[t]{2}{*}{ P-value } \\
\hline & B & SE & & & \\
\hline Constant & 0.521 & 0.127 & & 4.094 & 0.000 \\
\hline Age & 0.000 & 0.001 & 0.026 & 0.360 & 0.719 \\
\hline Pain intensity before the surgery & 0.038 & 0.010 & 0.263 & 3.743 & $<0.00 I^{*}$ \\
\hline $\begin{array}{l}\text { Severity of the procedure } \\
\text { (simpler vs more complex) }\end{array}$ & $0.08 \mathrm{I}$ & 0.065 & 0.086 & 1.234 & 0.219 \\
\hline Work status & -0.032 & 0.020 & -0.105 & -1.562 & 0.120 \\
\hline Premedication before the surgery & -0.075 & 0.031 & $-0.17 \mid$ & -2.397 & $0.018^{*}$ \\
\hline Type of anesthesia & -0.134 & 0.031 & -0.335 & -4.348 & $<0.00 I^{*}$ \\
\hline Total result on the PCS & 0.003 & 0.001 & 0.184 & 2.601 & $0.010 *$ \\
\hline Positive affect on the PANAS & 0.001 & 0.002 & 0.025 & 0.397 & 0.692 \\
\hline Negative affect on the PANAS & 0.002 & 0.002 & 0.025 & 0.632 & 0.528 \\
\hline Total result on anxiety scale & -0.002 & 0.003 & -0.033 & -0.478 & 0.634 \\
\hline Extraversion on IPIP & -0.002 & 0.002 & -0.049 & -0.755 & 0.439 \\
\hline Intellect/imagination on IPIP & -0.002 & 0.003 & $-0.04 \mid$ & -0.644 & 0.521 \\
\hline
\end{tabular}

Notes: *Statistically significant result $(P<0.05)$; adjusted $R$ square $=0.730, F=|5.201, d f|=|2, d f 2=| 78, P<0.001$. Independent $t$-test statistics provided information to determine whether regression coefficients significantly differ from zero.

Abbreviations: PCS, Pain Catastrophizing Scale; PANAS, Positive and Negative Affect Schedule; IPIP, International Personality Item Pool. 
significant negative correlation with intellect/imagination (Pearson $r=-0.227 ; P=0.001$ ) and significant negative correlation with extraversion (Pearson $r=-0.160 ; P=0.018$ ).

Significantly, longer postoperative pain duration was found in patients who underwent more complex procedures compared to the simple ones (Mann-Whitney $U=206$; $P<0.001)$, who had poorer subjective self-assessment of health $\left(\chi^{2}=9.046, d f=3, P=0.029\right)$, who did not get any premedication before their surgery (Mann-Whitney $U=3,191$; $P<0.001$ ), those operated under general anesthesia compared to patients operated under local anesthesia (Mann-Whitney $U=2,170 ; P<0.001$ ) and patients who did not receive analgesics before the surgery compared to those who did (Mann-Whitney $U=1,340 ; P=0.012$ ).

Variables that did not reach statistical significance related to postoperative pain duration were sex (MannWhitney $U=5,882 ; P=0.802$ ), height (Pearson $r=0.064$, $P=0.344$ ), weight (Pearson $r=0.062, P=0.361$ ), ASA status $\left(\chi^{2}=0.557 ; d f=2, P=0.757\right)$, education $\left(\chi^{2}=4.269, d f=2\right.$, $P=0.118)$, employment $\left(\chi^{2}=4.412, d f=2, P=0.110\right)$, income $\left(\chi^{2}=2.901, d f=2, P=0.234\right)$, magnification sub-scale of pain catastrophizing (Pearson $r=0.117 ; P=0.082$ ), as well as personality dimensions agreeableness (Pearson $r=-0.098$; $P=0.145$ ), conscientiousness (Pearson $r=0.040 ; P=0.556$ ) and emotional stability (Pearson $r=-0.116 ; P=0.084$ ).

Significant predictors from the univariate analysis were further studied in a multivariate analysis. According to the results of multivariate analysis, independent predictors of longer postoperative pain duration were pain intensity before the surgery, type of anesthesia and subjective self-assessment of health. Patients operated in local anesthesia have shorter pain duration, higher pain intensity before the surgery predicts postoperative pain duration, and patients who self-assessed their health as poor had a longer postoperative pain duration (Table 5).

\section{Factors associated with postoperative pain intensity $\geq 5$ within the first 6 hours after surgery}

On the univariate level, a number of factors were associated with postoperative pain intensity $\geq 5$ within the first 6 hours after surgery, including sex, type of procedure, education, employment, subjective self-assessment of health, receiving therapy before the surgery, type of anesthesia, preoperative pain intensity, pain catastrophizing, positive and negative effect and personality dimensions conscientiousness, and intellect/imagination.

Pain intensity $\geq 5$ within the first 6 hours after surgery is reported more frequently by women than by men $(\mathrm{OR}=0.445$, 95\% CI: 0.229 to $0.865, P=0.017$ ), patients undergoing complex procedures compared to simpler ones $(\mathrm{OR}=38.054,95 \%$ CI: 4.619 to $313.521, P=0.001)$. Patients with lower level of education, ie, those with primary school and without primary school (OR $=5.692,95 \% \mathrm{CI}: 1.234$ to $26.268, P=0.026)$ and those with high school (OR $=5.676,95 \%$ CI: 1.283 to 25.104 , $P=0.022$ ) have higher probability of having pain intensity $\geq 5$ within the first 6 hours after surgery than those of higher educational level (college, $\mathrm{PhD}$, etc). Higher probability

Table 5 Results of multivariate analysis on independent predictors of postoperative pain duration

\begin{tabular}{|c|c|c|c|c|c|}
\hline \multirow[t]{2}{*}{ Model } & \multicolumn{2}{|c|}{$\begin{array}{l}\text { Nonstandardized } \\
\text { coefficients }\end{array}$} & \multirow{2}{*}{$\begin{array}{l}\text { Standardized } \\
\text { coefficients } \\
\text { Beta }\end{array}$} & \multirow[t]{2}{*}{$t$-test } & \multirow[t]{2}{*}{$P$-value } \\
\hline & B & SE & & & \\
\hline Constant & 6.812 & 1.658 & & 4.109 & 0.000 \\
\hline Age (years) & 0.004 & 0.013 & 0.017 & 0.282 & 0.778 \\
\hline Pain intensity before the surgery & 0.511 & 0.137 & 0.253 & 3.728 & $<0.00 I^{*}$ \\
\hline $\begin{array}{l}\text { Severity of the procedure } \\
\text { (simpler vs more complex) }\end{array}$ & -0.014 & 0.907 & -0.001 & -0.016 & 0.987 \\
\hline Self-assessment of health & 0.601 & 0.208 & 0.160 & 2.892 & 0.004 \\
\hline Premedication before the surgery & 0.101 & 0.408 & 0.017 & 0.247 & 0.805 \\
\hline Type of anesthesia & -2.902 & 0.418 & -0.526 & -6.947 & $<0.00 I^{*}$ \\
\hline Total result on the PCS & 0.028 & 0.016 & 0.124 & 1.808 & 0.072 \\
\hline Positive affect on the PANAS & 0.007 & 0.024 & 0.018 & 0.295 & 0.768 \\
\hline Negative affect on the PANAS & 0.007 & 0.034 & 0.015 & 0.197 & 0.844 \\
\hline Total result on anxiety scale & -0.028 & 0.042 & -0.044 & -0.653 & 0.514 \\
\hline Extraversion on the IPIP & -0.012 & 0.031 & -0.024 & -0.378 & 0.706 \\
\hline Intellect/imagination on the IPIP & -0.037 & 0.034 & -0.070 & -1.097 & 0.274 \\
\hline
\end{tabular}

Notes: *Statistically significant result $(P<0.05)$ adjusted $R$ square $=0.421, d f|=| 2, d f 2=202, F=\mid 3.958, P<0.001$. Independent $t$-test statistics provided information to determine whether regression coefficients significantly differ from zero.

Abbreviations: PCS, Pain Catastrophizing Scale; PANAS, positive and negative affect schedule; IPIP, International Personality Item Pool. 
of pain intensity $\geq 5$ within the first 6 hours after surgery was found in employed patients compared to unemployed and retired patients (OR $=1.199,95 \%$ CI: 1.199 to 8.365 , $P=0.020$ ), patients operated under general anesthesia compared to those operated under local anesthesia $(\mathrm{OR}=12.148$, 95\% CI: 4.174 to $35.360, P<0.001)$. Lower probability of pain intensity $\geq 5$ within the first 6 hours after surgery was found in patients who self-assessed their health as good ( $\mathrm{OR}=0.225,95 \% \mathrm{CI}: 0.061$ to $0.833, P=0.025)$ and those who received premedication before the surgery ( $O R=0.201$, 95\% CI: 0.101 to $0.401, P<0.001)$. Patients with higher preoperative pain intensity more frequently reported pain intensity $\geq 5$ within the first 6 hours after surgery (MannWhitney $U=2,656.5, P<0.001$ ), as well as patients with higher total Pain Catastrophizing Scores (Mann-Whitney $U=2,962, P=0.008)$ and pain catastrophizing subscales rumination (Mann-Whitney $U=2,765, P<0.001$ ) and helplessness (Mann-Whitney $U=3,122.5, P=0.025$ ). According to the independent $t$-test, lower positive affect on the PANAS scale was associated with pain intensity $\geq 5$ within the first 6 hours after surgery $(t=3.58, d f=220, P<0.001)$, as well as higher level of negative affect (Mann-Whitney $U=3,191, P=0.044)$. Among personality dimension measured with the IPIP scale, $t$-test indicated that patients with pain intensity $\geq 5$ within the first 6 hours after surgery were more conscientious $(t=-2.06, d f=220, P=0.040)$ and scored lower for the intellect/imagination $(t=2.41, d f=219, P=0.017)$.
A number of investigated variables were not significantly associated with pain intensity $\geq 5$ within the first 6 hours after surgery on the univariate level. Compared to poorer ASA status, ASA 1 status $(\mathrm{OR}=1.560,95 \% \mathrm{CI}$ : $0.510-4.770, P=0.435)$ and ASA 2 status $(\mathrm{OR}=1.800$ 95\% CI: $0.487-6.649, P=0.378)$ were not associated with pain intensity $\geq 5$ within the first 6 hours after surgery, and neither did magnification subscale of the pain catastrophizing (Mann-Whitney $U=3,507, P=0.214$ ), height ( $t=1.05, d f=220, P=0.295)$, weight $(t=0.39, d f=220$, $P=0.699)$, income under 750 USD (OR $=0.844,95 \% \mathrm{CI}$ : 0.090-8.904, $P=0.882$ ), income between 751 and 1,499 USD ( $\mathrm{OR}=1.206,95 \% \mathrm{CI}: 0.127$ to $11.452, P=0.870$ ), personality dimensions agreeableness $(t=0.17, d f=219, P=0.867)$, extraversion $(t=1.85, d f=216, P=0.065)$ and emotional stability $(t=0.66, d f=57.836, P=0.442)$.

According to the multivariate analysis, independent predictors of pain intensity $\geq 5$ within the first 6 hours after surgery were type of procedure, education, self-assessment of health, premedication before the surgery and pain catastrophizing. Undergoing a complex surgical procedure, having lower level of education (high school, primary school or without primary school compared to college level/PhD), poorer self-assessment of health, not receiving premedication before the surgery and having higher Pain Catastrophizing Scores independently predicts occurrence of pain intensity $\geq 5$ within the first 6 hours after surgery (Table 6).

Table 6 Results of multivariate analysis on independent predictors of postoperative pain intensity $\geq 5$ within the first 6 hours after surgery

\begin{tabular}{|c|c|c|c|c|c|}
\hline \multirow[t]{2}{*}{ Model } & \multicolumn{2}{|c|}{$\begin{array}{l}\text { Nonstandardized } \\
\text { coefficients }\end{array}$} & \multirow{2}{*}{$\begin{array}{l}\text { Standardized } \\
\text { coefficients } \\
\text { Wald }\end{array}$} & \multirow[t]{2}{*}{$d f$} & \multirow[t]{2}{*}{$P$-value } \\
\hline & B & SE & & & \\
\hline Constant & -5.337 & 3.722 & 2.056 & 1 & 0.005 \\
\hline Male sex & 0.949 & 0.630 & $2.27 I$ & 1 & 0.132 \\
\hline Higher pain intensity before the surgery & 0.137 & 0.270 & 0.257 & 1 & 0.612 \\
\hline More complex procedure & -3.934 & 1.545 & 6.485 & 1 & $0.01 I^{*}$ \\
\hline $\begin{array}{l}\text { Primary school education or without } \\
\text { primary school }\end{array}$ & 4.654 & 1.760 & 6.990 & I & $0.008 *$ \\
\hline High school education & 3.657 & 1.569 & 5.431 & 1 & $0.20 *$ \\
\hline Being employed & 1.099 & 0.838 & 1.720 & 1 & 0.190 \\
\hline Being unemployed & -0.801 & 0.827 & 0.938 & 1 & 0.333 \\
\hline Very good health on self-assessment & -3.605 & 1.614 & 4.988 & $\mathrm{I}$ & $0.026^{*}$ \\
\hline Good health on self-assessment & -2.540 & 1.287 & 3.895 & 1 & $0.048 *$ \\
\hline General anesthesia & 1.433 & 0.899 & 2.543 & 1 & 0.111 \\
\hline Receiving premedication before the surgery & 1.905 & 0.711 & 7.172 & 1 & $0.007^{*}$ \\
\hline Total result on the PCS & 0.079 & 0.033 & 5.764 & 1 & $0.016^{*}$ \\
\hline Positive affect on the PANAS & -0.087 & 0.047 & 3.401 & 1 & 0.065 \\
\hline Negative affect on the PANAS & -0.036 & 0.054 & 0.444 & 1 & 0.505 \\
\hline Conscientiousness & 0.107 & 0.058 & 3.477 & I & 0.062 \\
\hline Intellect/imagination & 0.036 & 0.058 & 0.382 & I & 0.536 \\
\hline
\end{tabular}

Notes: *Statistically significant result $(P<0.05) ; \chi^{2}=84.382, d f=17, P<0.00$ I; Cox and Snell $R$ square $=0.350$; Nagelkerke $R$ square $=0.569$.

Abbreviations: PCS, Pain Catastrophizing Scale; PANAS, positive and negative affect schedule. 


\section{Discussion}

The purpose of this study was analysis of factors associated with pain intensity, pain duration, and consumption of analgesics after ophthalmic surgery. According to Ip et al, such factors need to be determined before the surgery. ${ }^{11}$ Henzler et al have shown that the postoperative pain intensity is highest within the first 6 hours from surgery. ${ }^{8}$ Since these surgical procedures are performed on the eyes, it is not realistic that patients can fill out questionnaires in the early postoperative period.

Based on the multivariate analyses performed within this study, independent predictors of average postoperative pain intensity were not receiving premedication, surgery under general anesthesia, higher preoperative pain intensity, and higher pain catastrophizing level. Independent predictors of postoperative pain duration were higher preoperative pain intensity, general anesthesia, and poorer self-assessment of health, while independent predictors of postoperative pain intensity $\geq 5$ within the first 6 hours after surgery were more complex procedure, lower level of education, poorer selfassessment of health, not receiving premedication before the surgery, and having higher Pain Catastrophizing Scores.

A recent systematic review on independent predictive factors for postoperative pain and analgesic consumption in various types of surgical procedures included 48 primary studies with 23,037 patients. ${ }^{11}$ Preoperative pain intensity, anxiety, age, and type of surgery were found to be significant predictors for postoperative pain, while sex was not found to be a consistent predictor, as it was previously traditionally believed. That review identified many gaps in the literature on independent factors in postoperative pain. However, it did not provide sufficient information about postoperative pain in ophthalmic surgery due to lack of adequate studies from that field. ${ }^{11}$

Earlier studies on factors associated with postoperative pain in ophthalmic surgery revealed a lack of studies in this field. ${ }^{12}$ The systematic review of Lesin et al recommended that future studies on factors associated with postoperative pain and analgesic consumption in ophthalmic surgery need to include adequate statistics for assessment of independent factors. The use of numerical rating scale was recommended because a patient may have a temporary sight impairment after ophthalmic surgery and therefore VAS may not be appropriate in these surgical patients. ${ }^{12}$ It was also recommended to study postoperative pain multiple times after surgery, especially during first 6 hours from the surgery because it has been shown that postoperative pain intensity is the highest in ophthalmic patients within that time frame. ${ }^{8}$
Furthermore, it has been recommended to explore the multiple factors that have already been identified as important for the development of postoperative pain in other fields of surgery, such as sociodemographic, psychological, surgeryrelated, and anesthesia-related factors. ${ }^{12}$

Age is an important factor to be measured in the context of pain. Due to population aging, it has been suggested that research into the assessment of postoperative pain in older patients is urgently needed. ${ }^{13}$ We did not find age or sex to be independently associated with postoperative pain intensity and duration. Although age and sex are traditionally believed to be predictors for postoperative pain and analgesic consumption, the results of the recent systematic review showed that the results from the different studies were conflicting for those two predictors. A probable explanation is difference in sampling population. ${ }^{11}$ A study of Ip et al summarized in a systematic review, all the independent predictors related to postoperative pain in various types of surgeries. They found that age was explored in six studies and all six found a correlation. However, on the subject of sex they found three studies that used appropriate methods for analyzing independent factors associated with postoperative pain and those results were inconsistent between studies..$^{11}$ A recent review about pain and sex indicated that there are still many inconsistencies between studies on this topic both in the field of clinical and experimental pain. ${ }^{14}$

Anxiety was identified as an important predictor for the development of postoperative pain, especially in gastrointestinal, obstetrical, and gynecological surgery. ${ }^{11}$ It has been described that anxious state leads to increased reactivity to pain, supporting the view that emotional states modulate human pain reactivity. ${ }^{15}$ In this study, anxiety was associated with average postoperative pain intensity and duration on univariate level, but multivariate analyses did not find it independently associated with postoperative pain intensity and duration.

Pain catastrophizing is an important determinant of intrapersonal aspects of pain, including increased pain intensity, distress, and disability. ${ }^{16}$ According to the communal coping model, pain catastrophizing is described as being part of a broader, interpersonal or communal coping style, in which it serves a social communicative function. ${ }^{16}$ Catastrophizing has been broadly defined as an exaggerated negative mental set brought to bear during actual or anticipated pain experience. ${ }^{16}$ High levels of pain catastrophizing were found to be associated with increased pain severity, increased incidence of development of chronic pain, and poorer quality of life after surgery. However, there was no consensus on the association 
between catastrophizing and analgesia consumption. ${ }^{17}$ In this study, we showed that pain catastrophizing was independently associated with average postoperative pain intensity, postoperative pain duration, and experiencing intensive pain within the first 6 hours after surgery.

Pain catastrophizing has been already described as an independent predictor of postoperative pain in other types of surgery, such as gynecologic laparoscopy for nonacute pelvic pain. ${ }^{18}$ total knee arthroplasty, ${ }^{19}$ elective instrumented lumbar fusion surgery, ${ }^{20}$ and heterogeneous elective surgical procedures. $^{21}$

Factors underlying individual differences in pain responding are incompletely understood, but are likely to include factors such as personality. ${ }^{22}$ Certain personality traits, such as neuroticism and hostility, were found to have a positive correlation with both postoperative pain ${ }^{23,24}$ and analgesic consumption. ${ }^{25}$ Different personality traits in this study were associated with postoperative pain intensity and duration on univariate level, but it was not established as an independent predictor of postoperative pain intensity and duration.

The analysis of personality traits and pain catastrophizing as important determinants of intra-personal aspects of pain adds to the novelty of our work because this type of analysis has been validated only in non-ophthalmic surgery previously.

Increasing consumption of analgesics in Croatia has been recently reported, ${ }^{26}$ but our study also points out that there are still deficiencies in pain treatment following surgery. Even though there is evidence that prescribing patterns are changing, ${ }^{27}$ there is still plenty to be done in the field of postoperative pain management. It is important to study risk factors associated with various conditions in multiple settings, ${ }^{28}$ so that clinicians can adjust their decision-making.

The limitations of our study include its study design, whereas there was no control group. There may be many additional factors influencing the pain intensity and duration, such as experience with earlier surgery and surgery duration, which were not tested in this particular study. Additionally, postoperative pain experience may be influenced by the hospital procedures as well. For example, a third of patients included in this study did not receive benzodiazepines as a premedication. We have already shown before that there is a lack of compliance with perioperative pain management guidelines in this setting. ${ }^{9}$

\section{Conclusion}

A number of independent predictors associated with average postoperative pain intensity, postoperative pain duration and occurrence of intensive pain after ophthalmic surgery were identified. Awareness about these factors may help health workers to improve postoperative pain management in ophthalmic surgery.

\section{Disclosure}

The authors report no conflicts of interest in this work.

\section{References}

1. Fletcher D, Fermanian C, Mardaye A, Aegerter P. A patient-based national survey on postoperative pain management in France reveals significant achievements and persistent challenges. Pain. 2008; 137(2):441-451

2. Benhamou D, Berti M, Brodner G, et al. Postoperative Analgesic THerapy Observational Survey (PATHOS): a practice pattern study in 7 central/southern European countries. Pain. 2008;136(1-2):134-141.

3. Awan H, Durrani Z. Postoperative pain management in the surgical wards of a tertiary care hospital in Peshawar. J Pak Med Assoc. 2015;65(4):358-361.

4. Apfelbaum JL, Chen C, Mehta SS, Gan TJ. Postoperative pain experience: results from a national survey suggest postoperative pain continues to be undermanaged. Anesth Analg. 2003;97(2):534-540.

5. Brennan F, Carr DB, Cousins M. Pain management: a fundamental human right. Anesth Analg. 2007;105(1):205-221.

6. Coppens M, Versichelen L, Mortier E. Treatment of postoperative pain after ophthalmic surgery. Bull Soc Belge Ophtalmol. 2002;(285): $27-32$.

7. Henry C, Navarro V, Jun A, Annaberdyev S. Measuring the "fifth vital sign" in cataract surgery patients - is it necessary? Insight. 2006; 31(2):7-9.

8. Henzler D, Kramer R, Steinhorst UH, Piepenbrock S, Rossaint R, Kuhlen R. Factors independently associated with increased risk of pain development after ophthalmic surgery. Eur J Anaesthesiol. 2004; 21(2):101-106.

9. Lesin M, Sundov ZD, Jukic M, Puljak L. Postoperative pain in complex ophthalmic surgical procedures: comparing practice with guidelines. Pain Med. 2014;15(6):1036-1042.

10. Aslan L, Aslankurt M, Cekic O, Aksoy A, Yildiz H. The pain experience and cooperation of patients in consecutive cataract surgery. EurJ Ophthalmol. 2013;23(3):339-343.

11. Ip HY, Abrishami A, Peng PW, Wong J, Chung F. Predictors of postoperative pain and analgesic consumption: a qualitative systematic review. Anesthesiology. 2009;111(3):657-677.

12. Lesin M, Domazet Bugarin J, Puljak L. Factors associated with postoperative pain and analgesic consumption in ophthalmic surgery: A systematic review. Surv Ophthalmol. 2015;60(3):196-203.

13. Gagliese L, Weizblit N, Ellis W, Chan VW. The measurement of postoperative pain: a comparison of intensity scales in younger and older surgical patients. Pain. 2005;117(3):412-420.

14. Fillingim RB, King CD, Ribeiro-Dasilva MC, Rahim-Williams B, Riley JL 3rd. Sex, gender, and pain: a review of recent clinical and experimental findings. J Pain. 2009;10(5):447-485.

15. Rhudy JL, Meagher MW. Fear and anxiety: divergent effects on human pain thresholds. Pain. 2000;84(1):65-75.

16. Sullivan MJ, Thorn B, Haythornthwaite JA, et al. Theoretical perspectives on the relation between catastrophizing and pain. Clin J Pain. 2001;17(1):52-64.

17. Chung JWY, Lui JCZ. Postoperative pain management: study of patients' level of pain and satisfaction with health care providers' responsiveness to their reports of pain. Nurs Health Sci. 2003;5(1):13-21.

18. Jarrell J, Ross S, Robert M, et al. Prediction of postoperative pain after gynecologic laparoscopy for nonacute pelvic pain. Am J Obstet Gynecol. 2014;211(4):360.e361-e368. 
19. Lunn TH, Gaarn-Larsen L, Kehlet H. Prediction of postoperative pain by preoperative pain response to heat stimulation in total knee arthroplasty. Pain. 2013;154(9):1878-1885.

20. Papaioannou M, Skapinakis P, Damigos D, Mavreas V, Broumas G, Palgimesi A. The role of catastrophizing in the prediction of postoperative pain. Pain Med. 2009;10(8):1452-1459.

21. Sommer M, de Rijke JM, van Kleef M, et al. Predictors of acute postoperative pain after elective surgery. Clin J Pain. 2010;26(2):87-94.

22. Vassend O, Roysamb E, Nielsen CS. Five-factor personality traits and pain sensitivity: a twin study. Pain. 2013;154(5):722-728.

23. Gong L, Dong JY. Patient's personality predicts recovery after total knee arthroplasty: a retrospective study. J Orthop Sci. 2014;19(2):263-269.

24. Liu D. A comparison of implant extrusion rates and postoperative pain after evisceration with immediate or delayed implants and after enucleation with implants. Trans Am Ophthalmol Soc. 2005;103:568-591.
25. Taenzer $P$, Melzack R, Jeans ME. Influence of psychological factors on postoperative pain, mood and analgesic requirements. Pain. 1986;24(3): 331-342.

26. Krnic D, Anic-Matic A, Dosenovic S, Zezelic P, Draganic S, Puljak L. National consumption of opioid and nonopioid analgesics in Croatia: 2007-2013. Ther Clin Risk Manag. 2015;11:1305-1314.

27. Gudin JA. The changing landscape of opioid prescribing: long-acting and extended-release opioid class-wide Risk Evaluation and Mitigation Strategy. Ther Clin Risk Manag. 2012;8:209-217.

28. Brkovic E, Novak K, Puljak L. Pain-to-hospital times, cardiovascular risk factors, and early intrahospital mortality in patients with acute myocardial infarction. Ther Clin Risk Manag. 2015;11:209-216.

\section{Publish your work in this journal}

Therapeutics and Clinical Risk Management is an international, peerreviewed journal of clinical therapeutics and risk management, focusing on concise rapid reporting of clinical studies in all therapeutic areas outcomes, safety, and programs for the effective, safe, and sustained use of medicines. This journal is indexed on PubMed Central, CAS,
EMBase, Scopus and the Elsevier Bibliographic databases. The manuscript management system is completely online and includes a very quick and fair peer-review system, which is all easy to use. Visit http://www.dovepress.com/testimonials.php to read real quotes from published authors. 